\title{
Korelasi Inovasi dan Kinerja pada Industri Kecil dan Menengah: Kajian Meta-Analisis
}

\author{
Trifandi Lasalewo ${ }^{1}$ \\ Jurusan Teknik Industri Universitas Negeri Gorontalo \\ Avin Fadilla Helmi \\ Fakultas Psikologi Universitas Gadjah Mada
}

\begin{abstract}
The effect of innovation on performance of Small and Medium Industries (SMIs) draws a great of attention from researchers and practitioners to study further. Based on empirical findings, it is found out that the correlation between innovation and performance is dependent on context, that is the innovation does not affect the performance of a company or indicated negative implication between innovation and performance. Meanwhile, other researches reported positive effects of innovation and performance. The review of researches on the correlation between innovation and SMIs performance shows contradictory results. The meta-analytical study is aimed at investigating further the correlation between innovation and performance on SMI based on researches published between 2004 and 2013 in 5 continents (Australia, Asia, Europe, Africa and America). The independent variable was innovation and the dependent variable was performance, while the moderators variable consisted of the year of the research and the location of survei. The result of the meta-analytical study on the correlation between innovation and performance indicated a positive correlation with mean 0.459 and the standard deviation 0.168 on $95 \%$ confidence interval.
\end{abstract}

Keywords: inovation, performance, SMIs, meta-analysis

\section{Pengantar}

Keberhasilan wirausaha ditandai melalui pencarian karakteristik inovasi, perbaikan proses produksi dan model bisnis. Inovasi adalah atribut kunci untuk dapat bertahan dan bersaing dalam persaingan yang makin tinggi, dimana inovasi merupakan salah satu solusi (Rosenbusch Brinckmann, \& Bausch, 2011).

Berdasarkan beberapa penelitian terdahulu, bahwa inovasi sangat dibutuhkan

\footnotetext{
1 Korespondensi mengenai isi artikel ini dapat melalui: trifandilasalewo@gmail.com
}

oleh para pemilik/pengusaha industri kecil dan menengah (IKM) atau manajer agar dapat bersaing dengan perusaan besar yang telah mapan. Para peneliti juga mengingatkan bahwa inovasi menuntut banyak sumber daya yang substansial, sedangkan sumber daya merupakan sesuatu yang langka bagi perusahaan kecil. Selain itu inovasi memiliki dampak yang tidak pasti dan berisiko (Eisenhardt \& Martin, 2000).

Studi ini menggunakan pendekatan meta-analisis, bertujuan untuk mencari hubungan antara inovasi dengan kinerja perusahaan (khususnya IKM), melalui 25 studi empiris, pada lima benua yakni 
Australia, Asia, Eropa, Afrika dan Amerika, dengan data publikasi penelitian antara Tahun 2004-2013. Apakah terdapat korelasi antara inovasi dengan kinerja? Variabel moderator potensial apa saja yang mungkin timbul dari hasil kajian ini?

Untuk mengatasi ini, meta-analisis merupakan alat yang cukup baik dan sistematis untuk mensitesa penelitianpenelitian sebelumnya, ditunjukkan melalui bukti-bukti yang bertujuan untuk mendukung temuan penelitian yang didasarkan pada agregasi. Meta-analisis adalah metode kuantitatif dan sistematis dikembangkan untuk mengintegrasikan temuan empiris masa lalu (Hunter \& Schmidt, 2004).

\section{Kajian Hasil Penelitian Inovasi Terdahulu}

Dilihat dari sudut pandang mikro, inovasi didefinisikan sebagai berikut: innovation is management discipline, it focuses on the organization's mission, searches for unique opportunities, determines whether they fit the organization's strategic direction, defines the measures for success, and continually reassesses opportunities (Gaynor, 2002). Kopalinski (2006) mendefinisikan, innovation sebagai introducing something new, the thing newly entered, novelty or reform. Inovasi menurut Drucker (2007) merupakan tool bagi wirausaha dalam membantu melakukan transformasi perubahan yang dapat menciptakan sebuah peluang dalam bentuk aktivitas baru atau pelayanan baru (Okwiet \& Grabara, 2013).

Lin dan Chen (2007) berpendapat bahwa inovasi adalah faktor dominan dalam persaingan dunia. Inovasi merupakan sumber daya pertumbuhan organisasi, yang mengarahkan keberhasilan masa depan perusahaan, dan sebagai alat yang dapat digunakan dalam persaingan global guna mempertahankan eksistensi perusahaan. Untuk mengejar ketertinggalan di era kompetisi ini, restrukturisasi, penghematan biaya (lower cost) dan perbaikan kualitas produk dan kualitas pelayanan merupakan suatu keharusan. Bahkan di Taiwan, usaha inovasi didukung sepenuhnya oleh pemerintah (melalui Industrial Development and Investment Center) dan kalangan akademisi. Hasilnya, Taiwan merupakan negara dengan jumlah paten terbanyak keempat selain Amerika, Jepang dan Jerman yang mendaftarkan hak patennya. Hal yang serupa juga dilakukan oleh Muscio (2006) dalam mengeksplorasi aktivitas dan pengaruh inovasi pada IKM di Italia.

Menurut Porter dan Stern (2001) bahwa kemampuan berkreasi serta kemampuan menciptakan produk dan proses baru (new products and processes) melalui pendekatan teknologi perlu dilakukan guna memenangkan persaingan. Untuk itu setiap perusahaan (terutama Industri Kecil dan Menengah) membutuhkan core competency yakni innovation. Hasil studi empiris yang dilakukan oleh Lin dan Chen (2007) bahwa inovasi dapat dilihat dari berbagai perspektif, misalnya: pengukuran inovasi organisasi berbasis inovasi produk, proses dan administratif (Maravelakis dkk., 2006), penelitian yang dilakukan oleh Woff dan Walker (2004) dan Walker (2005), membandingkan antara efek inovasi produk dan proses terhadap kinerja perusahaan, sedangkan Miller (2001) fokus meneliti inovasi produk dalam konteks industri manufaktur.

Dilihat dari perspektif organisasional, keberhasilan penerapan inovasi dilihat dari pangsa pasar, dimana inovasi dipandang sebagai proses transformasi good idea dan good product yang dapat meningkatkan penjualan dan profit. Merubah strategi inovasi merupakan kunci kesuksesan dalam penguasaan pasar. Selain itu, perusahaan juga harus berusaha untuk 
melembagakan inovasi dengan membangun budaya yang tepat, struktur, insentif, sistem, dan proses, yang menfasilitasi terjadinya inovasi sebagai bagian dari kegiatan bisnis sehari-hari. Dengan demikian bahwa kegiatan inovasi berkorelasi positif dengan kinerja perusahaan, khususnya IKM (Lin \& Chen, 2007).

Hal yang sama dikemukakan juga oleh Matic dan Jukic (2012) bahwa dalam konteks organisasi, inovasi dapat didefinisikan sebagai implementasi ide-ide baru yang menciptakan nilai positif baru bagi organisasi. Kegiatan inovasi memiliki pengaruf positif tarhadap kinerja bisnis dan bersifat unik antar satu perusahaan dan perusahaan lainnya, sangat tergantung dari perspektif yang digunakan.

Menurut Gaynor (2002) bahwa dalam berinovasi tidak dibutuhkan kejeniusan, tetapi sistem unik yang mendukung perubahan, kerja keras, fokus dan berorientasi pada tujuan. Berdasarkan studi yang dilakukan oleh Oke, Burke, dan Myers (2007) bahwa orientasi inovasi ditiap perusahaan berbeda-beda, yakni dapat dilakukan melalui inovasi produk, proses dan pelayanan (product, process, service). Hasil penelitian Oke dkk. (2007) bahwa fokus inovasi berkorelasi positif dengan kinerja perusahaan, dan ditekankan pada tiga tipe inovasi yakni inovasi penciptaan produk (new product), inovasi proses produksi (process) dan inovasi dalam bentuk layanan (service).

Menurut Rosenbusch dkk., (2011) bahwa inovasi internal dapat meningkatkan kinerja secara substansial, sedangkan kolaborasi dengan pihak eksternal tidak berpengaruh secara signifikan terhadap peningkatan kinerja. Kerjasama dengan mitra eksternal lebih baik bagi perusahaan kecil dan baru.

Berdasarkan uraian diatas, dapat disimpulkan bahwa inovasi sebagai proses transformasi dalam menciptakan product (barang) atau service (jasa layanan) yang baru (make the new) atau berbeda (different) dengan orang/perusahaan lainnya. Konsep inovasi inilah yang digunakan oleh peneliti dalam hipotesis kajian meta-analisis ini.

\section{Dampak Inovasi}

Penelitian Massa dan Testa (2008) bahwa atribut inovasi pada IKM dapat berbeda, tergantung kepentingan dan sudut pandangnya. Perbedaan tersebut dikaji dari perspektif pelaku usaha, akademisi, dan pembuat kebijakan/birokrat. Menurut pelaku usaha, "Innovation is anything that make money", menurut pembuat kebijakan "inovation is dream and risk", sedangkan menurut akademisi inovasi merupakan buah dari sebuah proses penelitian yang hanya dapat dilakukan pada universitas, pusat-pusat penelitian dan perusahaan besar.

Model formula inovasi juga dikembangkan oleh Tomlinson dan Fai (2013) yang membedakan definisi antara product innovation dengan process innovation, dimana product innovation adalah jumlah (kuantitas) produk yang diperkenalkan kepada konsumen, sedangkan process innovation adalah input teknologi/material baru yang digunakan dalam proses produksi.

Schiemann (2011) menemukan bahwa inovasi akan memicu dan berdampak pada peningkatan people equity. Berdasarkan temuan Sharabati dkk. (2010) bahwa inovasi dapat mempengaruhi human capital (sumber daya insani) dan human capital memengaruhi kinerja organisasi/ perusahaan.

\section{Business Performance}

Ukuran yang paling umum dari business performance yang berkaitan dengan 
inovasi dalam literatur adalah jumlah penjualan (sales turnover/omset penjualan), sedangkan ukuran bisnis seperti Return On Asset (ROA), Return On Equity (ROE), Return On Investment (ROI) dan sejenisnya, telah diabaikan karena kesulitan dalam menghubungkan ukuran tersebut dengan kegiatan inovasi. Untuk itu, para peneliti mengadopsi dua ukuran kuantitatif kinerja bisnis yakni sales turnover dan net profit before tax (Oke dkk., 2007).

Menurut Kraus Rigtering, Hughes, dan Hosman (2012) bahwa pemilihan indikator dalam mengukur kinerja bisnis IKM, dapat menentukan hubungan antara orientasi bisinis dan kinerja perusahaan. Dalam survei empiris banyak sekali indikator digunakan. Kinerja perusahaan biasanya diukur dari beberapa sisi yakni financial perceived (sudut pandang finansial), perceived non-financial dan archival financial, atau menggunakan perceived market turbulence sebagai ukuran kinerjanya.

Berdasarkan data empirik dan hasil pengamatan Kraus, dkk. (2012), para peneliti umumnya menggunakan lima idikator dalam mengukur kinerja bisnis (business performance) yakni: sales growth rate, employee growth, gross margin, profitability dan cash flow. Beberapa peneliti lain seperti Zahra dan Garvis (2000), Antoncic dan Hisrich (2004), Stam dan Elfring (2008) menggunakan umur perusahaan (firm age) dan ukuran perusahaan (firm size) sebagai variabel kontrol dalam model penelitiannya.

Pada studi empirik dengan pendekatan meta-analisis yang dilakukan oleh Rosenbusch dkk. (2011), melaporkan bahwa inovasi tidak mempengaruhi kinerja perusahaan (misalnya hasil penelitian Birley dan Westhead (1990); Heunks (1998), atau menemukan implikasi negatif antara inovasi-kinerja (misalnya, McGee dkk., (1995); Vermeulen dkk. (2005). Sementara itu penelitian lain melaporkan efek positif antara inovasi dengan kinerja (misalnya, penelitian DeCarolis dan Deeds, (1999); Guo dkk. (2005); Li dan Atuahene-Gima, (2001-2002)). Reviu tentang penelitian hubungan inovasi terhadap kinerja menggambarkan hal yang saling bertentangan, namun hingga saat ini hubungan terbaik adalah tidak ada.

\section{Posisi Penelitian}

Beberapa hasil penelitian mengenai korelasi antara inovasi dan kinerja perusahaan menunjukkan hasil yang kontradiktif. Sebagian studi memberikan kesimpulan bahwa inovasi berkorelasi positif terhadap kinerja perusahaan dan sebagian lainnya memberikan kesimpulan sebaliknya yaitu inovasi berkorelasi negatif terhadap kinerja perusahaan. Hal ini dibuktikan melalui survei empiris dengan pendekatan meta-analisis yang dilakukan oleh Rosenbusch dkk. (2011).

Kajian meta-analisis ini juga melakukan hal yang sama yakni mengukur korelasi antara inovasi dengan kinerja perusahaan, melalui survei empiris penelitian terdahulu, dengan referensi yang berbeda dengan penelitian Rosenbusch dkk. (2011). Hal lain yang membedakan kajian ini dengan kajian meta-analisis Rosenbusch dkk. (2011) yakni jenis variabel moderator yang digunakan dalam unit analisis. Uraian perbedaan ini secara detil diuraikan pada Tabel 1. 
Tabel 1

Posisi Penelitian

\begin{tabular}{|c|c|c|c|}
\hline No & Karakteristik & $\begin{array}{c}\text { Penelitian Rosenbusch dkk. } \\
\text { (2011) }\end{array}$ & Penelitian ini \\
\hline 1 & Tahun publikasi literatur & 1994-2009 & 2004-2013 \\
\hline 2 & Klasifikasi sistem tinjauan & Perusahaan/IKM baru & $\begin{array}{l}\text { Variatif (IKM baru dan IKM } \\
\text { lama/mapan) }\end{array}$ \\
\hline 3 & Sumber referensi & $\begin{array}{l}\text { Journal, working paper, } \\
\text { unpublished dissertation }\end{array}$ & $\begin{array}{l}\text { Jurnal dan proseding (sumber: } \\
\text { ProQuest dan ScienceDirect) }\end{array}$ \\
\hline 4 & Lokasi penelitian & Eropa, Asia, Amerika Serikat & $\begin{array}{l}\text { Australia, Asia, Eropa, Afrika } \\
\text { dan benua Amerika }\end{array}$ \\
\hline 5 & Variabel independen & Innovation (inovasi) & Inovasi \\
\hline 6 & Variabel dependen & Performance (kinerja) & Kinerja \\
\hline 7 & Variabel moderator & $\begin{array}{l}\text { Firm Age, Culture, Differences } \\
\text { beetwen innovation types }\end{array}$ & $\begin{array}{l}\text { Tahun Penelitian dan Lokasi } \\
\text { Survei }\end{array}$ \\
\hline
\end{tabular}

Pertanyaan Penelitian dan Hipotesis

Variasi nilai korelasi antara inovasi terhadap kinerja perusahaan menjadi kendala dalam pengambilan keputusan yang terkait dengan hubungan kedua variabel tersebut. Variasi ini menimbulkan keraguan atas keyakinan adanya korelasi positif antara inovasi dengan kinerja perusahaan.

Pertanyaan lain yang timbul akibat variasi di atas adalah apakah variasi tersebut diakibatkan oleh perbedaan jenis IKM (sistem tinjauan), tahun penelitian/ publikasi, atau lokasi survei penelitian? Tahun penelitian dapat memberikan pengaruh berbeda dalam konteks keterbukaan informasi dan teknologi dalam mengakses informasi. Lokasi dilakukan survei penelitian dapat berpengaruh dalam kaitannya dengan budaya dan karakteristik masyarakat suatu wilayah, serta keterbukaan responden/perusahaan dalam memberikan informasi yang dibutuhkan para peneliti. Oleh karena itu perlu dilakukan kajian untuk mendapatkan nilai korelasi yang sesungguhnya, melalui penelitian atas hipotesis-hipotesis berikut:

$\mathrm{H}_{1}$ : inovasi berkorelasi positif dengan kinerja perusahaan
$\mathrm{H}_{2}$ : tahun penelitian berkorelasi positif dengan kinerja perusahaan

$\mathrm{H}_{3}$ : lokasi penelitian berkorelasi positif dengan kinerja perusahaan

Hipotesis diatas secara korelasional dijelaskan pada Gambar 1 dan Gambar 2.

1. Melakukan meta-analisis atas data yang ada secara keseluruhan untuk menguji $\mathrm{H}_{1}$.

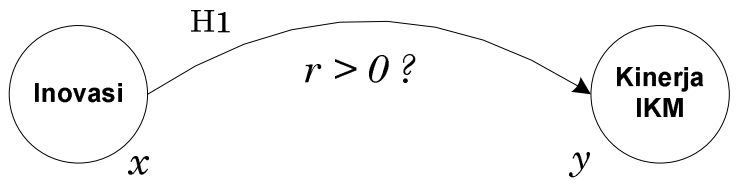

Gambar 1. Korelasi antara Inovasi dengan Kinerja IKM

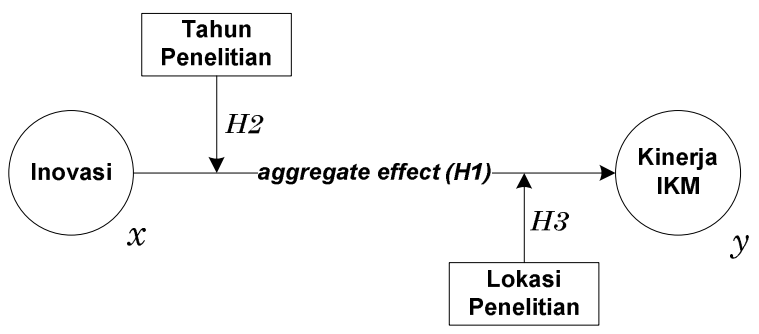

Gambar 2. Model Hipotesis Hubungan antar Variabel Penelitian 


\section{LASALEWO \& HELMI}

2. Melakukan meta-analisis analisis berdasarkan variabel yang berpotensi sebagai moderator untuk menguji $\mathrm{H}_{2}$ dan $\mathrm{H}_{3}$.

\section{Tool yang digunakan (Meta-analisis korelasi)}

Meta-analisis korelasi bertujuan untuk mendapatkan distribusi sesungguhnya dari korelasi antara suatu variabel independen dengan variabel dependen (Hunter \& Schmidt, 2004). Dalam kajian ini, variabel yang diukur adalah inovasi sebagai variabel independen $(x)$ dan kinerja perusahaan sebagai variabel dependen (y).

Studi individual tidak pernah sempurna karena beberapa artefak yang menyertainya, yaitu kesalahan pengambilan sam- pel, kesalahan pengukuran, dikotomisasi, rentang variasi variabel, deviasi struktur variabel, kesalahan transkrip, dan pengaruh eksternal lainnya. Kajian ini mencakup kesalahan pengambilan sampel yang merupakan kesalahan paling berpengaruh (Hunter \& Schmidt, 2004), serta kesalahan pengukuran. Tahapan meta-analisis korelasi secara ringkas digambarkan pada Gambar 3.

\section{Hasil Kajian}

Berikut studi yang digunakan sebagai sampel penelitian pada kajian metaanalisis.

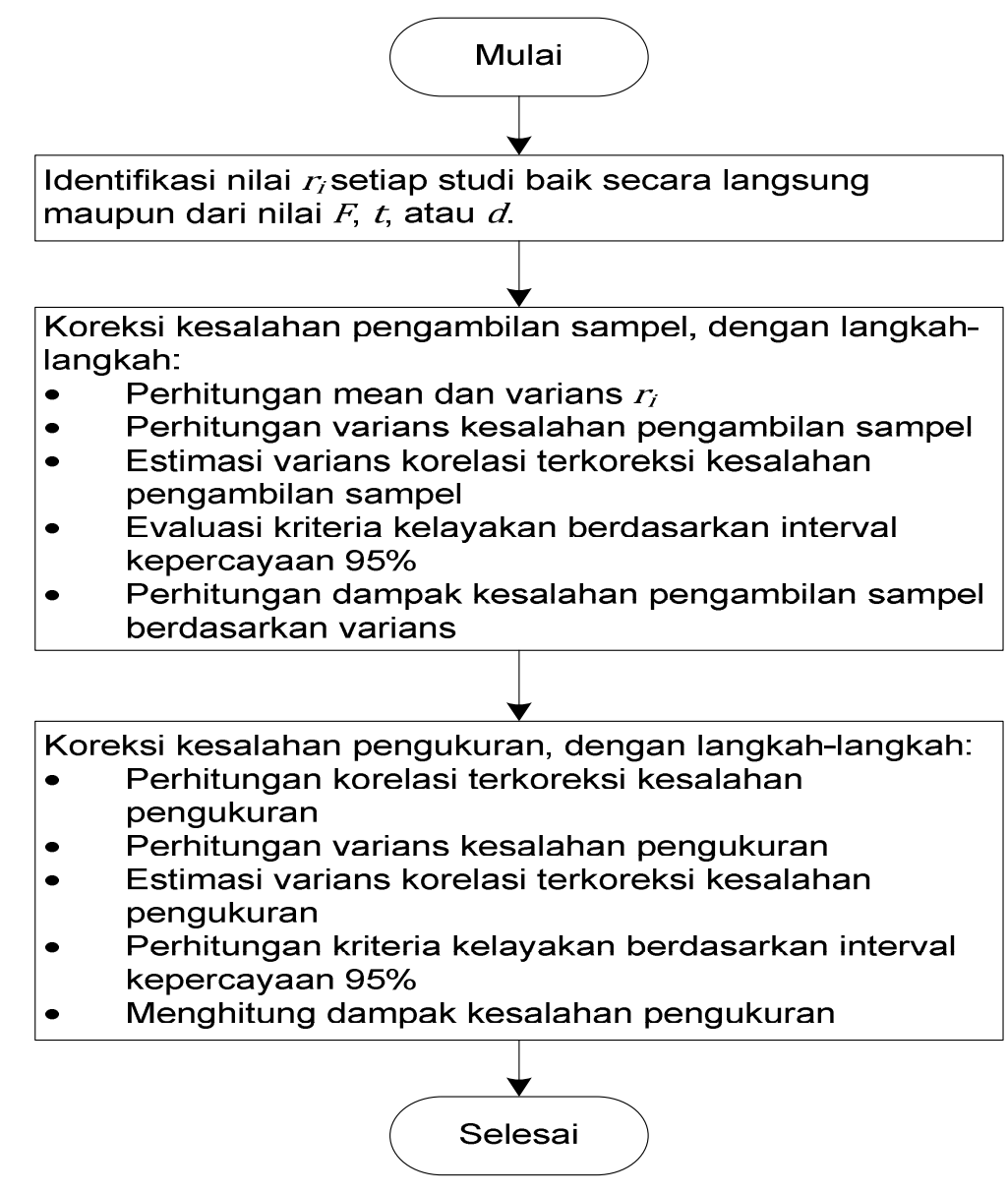

Gambar 3. Tahapan Pengolahan Data dengan Pendekatan Meta-Analisis (Hunter \& Schmidt, 2004). 
Tabel 2

Studi yang digunakan sebagai Sampel Penelitian

\begin{tabular}{|c|c|c|c|}
\hline Studi & Peneliti & $\begin{array}{c}\text { Tahun } \\
\text { Publikasi }\end{array}$ & Lokasi Penelitian \\
\hline 1 & Marcati dkk. & 2008 & Italia \\
\hline 2 & McDermott, C. M., \& Prajogo, D. I. & 2012 & Australia \\
\hline 3 & Mbizi dkk. & 2013 & Zimbabwe \\
\hline 4 & Prajogo dkk. & 2004 & Australia \\
\hline 5 & Dorrego dkk. & 2013 & Portugal \\
\hline 6 & Moghimi, S., \& Subramaniam, I. D & 2013 & Malaysia \\
\hline 7 & Salim, I. M., \& Sulaiman, M. & 2011 & Malaysia \\
\hline 8 & Gomez dkk. & 2011 & Spanyol \\
\hline 9 & Rajput, A.A & 2011 & Pakistan \\
\hline 10 & Najib, M. \& Kiminami, A. & 2011 & Jawa Barat, Indonesia \\
\hline 11 & Suliyanto, S. \& Rahab, R. & 2012 & Banyumas, Indonesia \\
\hline 12 & Ndubisi, N. O. \& Iftikhar, K. & 2012 & Pakistan \\
\hline 13 & Guzmán dkk. & 2012 & Meksiko \\
\hline 14 & Ferreira dkk. & 2012 & Portugal \& Spanyol \\
\hline 15 & Matic, I. \& Jukic, V. & 2012 & Bosnia \& Herzegovina \\
\hline 16 & Kraus dkk. & 2012 & Belanda \\
\hline 17 & Parida dkk. & 2011 & Swedia \\
\hline 18 & Carbonell, P. \& Escudero, A.I.R. & 2010 & Spanyol \\
\hline 19 & Cruz dkk. & 2009 & Spanyol \\
\hline 20 & Verhees, F. J. H. \& Meulenberg, M. & 2004 & Belanda \\
\hline 21 & Lin, C. Y. \& Chen, M. Y. & 2007 & Taiwan \\
\hline 22 & Mancinelli, S. \& Mazzanti, M. & 2009 & Italia \\
\hline 23 & Oke, dkk. & 2007 & United Kingdom \\
\hline 24 & Rosli, M. M. \& Mahmood, R. & 2013 & Malaysia \\
\hline 25 & Subramaniam, I. D. \& Moslehi, M. M. & 2013 & Malaysia \\
\hline
\end{tabular}

Observasi data pada 25 studi diatas dilakukan pada rentang tahun 2004 sampai dengan 2013. Lokasi observasi dari studi-studi tersebut mencakup benua Australia (2 studi), Asia (9 studi), Eropa (12 studi), Afrika (1 studi) dan benua Amerika (1 studi). Studi dilakukan pada IKM jenis manufaktur (makanan, konstruksi, tekstil, logam, kosmetik, kayu, communication networking, fast food, food processing, software firms, agriculture, clothing) dan IKM jenis non manufaktur/service (hotel, restoran), dengan responden yang bervariasi yakni owner (pemilik usaha), manejer, karyawan/ teknisi, supervisor dan Chief Executive Officers (CEOs).

\section{Meta-analisis Korelasi}

Meta-analisis korelasi bertujuan untuk mendapatkan distribusi sesungguhnya dari korelasi antara suatu variabel independen dengan variabel dependen (Hunter \& Schmidt, 2004). Dalam kajian ini, variabel yang dikaji adalah kontibusi inovasi (variabel independen) terhadap kinerja perusahaan/IKM (variabel dependen). 
Tahapan meta-analisis yang dilakukan dalam kajian ini adalah (Hunter \& Schmidt, 2004):

1. Mengidentifikasi nilai $r_{i}$ setiap studi baik secara langsung maupun dari nilai $F, t$, atau $d$ melalui persamaan (1a), (1b), dan/atau (1c).

$$
\begin{aligned}
t_{i} & =\sqrt{F_{i}} \\
d_{i} & =\frac{2 t_{i}}{\sqrt{N_{i}}} \\
r_{i} & =\frac{d_{i}}{\sqrt{\left(4+d_{i}^{2}\right)}}
\end{aligned}
$$

dengan

$x=$ variabel independen

$y=$ variabel dependen

$r_{i} \quad=$ korelasi $x$ dan $y$ pada studi ke- $i$

$F_{i}=$ F statistik $x$ terhadap $y$ pada studi ke$i$

$t_{i}=\mathrm{t}$ statistik $x$ terhadap $y$ pada studi ke$i$

$d_{i}=$ effect size

$N_{i}=$ ukuran sampel studi ke- $i$

Menurut Hunter dan Schmidt (2004) bahwa informasi statistik yang harus ada dalam setiap studi metaanalisis adalah ukuran sampel dan effect size. Effect size yang diperlukan adalah $r$. Namun demikian, jika tidak ada informasi $r$, effect size yang lain yaitu $d, t$, atau $F$ dapat pula digunakan untuk kemudian dikonversikan dengan persamaan (1a), (1b), dan/atau (1c). Dimana nilai $F, t$ dan $d$ diperoleh dari data sekunder yang ada pada referensi penelitian dan selanjutnya diturunkan menggunakan persamaan (1a), (1b), dan (1c).

Semakin banyak jumlah sampel yang digunakan dalam suatu penelitian meta-analisis, maka akan semakin baik, karena lebih representatif dan menggambarkan sistem tinjaun dalam skala yang lebih luas. Data pada studi meta analisis ini dianggap sudah cu- kup representatif, karena mewakili benua Australia, Asia, Eropa, Afrika dan benua Amerika sebagai unit analisisnya.

2. Melakukan koreksi kesalahan pengambilan sampel

Kesalahan dalam pengambilan sampel (sampling eror) adalah artefak yang paling banyak mencemari hasil penelitian. Menurut Hunter dan Schmidt (2004) bahwa kesalahan sampling ini memberikan dampak tidak terstruktur dan sangat dipengaruhi oleh besarnya ukuran sampel yang digunakan. Oleh karena itu, koreksi terhadap kesalahan dalam pengambilan sampel, penting untuk dilakukan terhadap data penelitian mengenai variabel yang sama sehingga diperoleh pola hubungan yang lebih konsisten mengenai variabel yang diuji.

Koreksi kesalahan pengambilan sampel dilakukan dengan langkahlangkah berikut:

a. Menghitung mean $r_{i}$ (rerata korelasi populasi)

$$
r=\frac{\Sigma N_{i} r_{i}}{\Sigma N_{i}}
$$

dengan

$r_{i}=$ korelasi $x$ dan $y$ pada studi ke- $i$

$N_{i}=$ ukuran sampel studi ke- $i$

Untuk menghitung koreksi kesalahan pengambilan sampel, ditunjukkan pada Tabel 3.

Rerata korelasi populasi setelah dikoreksi dengan jumlah sampel $(\tilde{r})$ sebesar 0,400. Nilai ini menunjukkan fakta bahwa inovasi merupakan variabel yang sangat mempengaruhi kinerja IKM. Jika dilihat dari jumlah sampel, studi meta-analisis ini sudah memenuhi syarat secara teoritis yakni sebanyak 4.696 buah, sebab menurut Hunter dan Schmidt (2004) ukuran 
Tabel 3

Koreksi Kesalahan Sampling

\begin{tabular}{|c|c|c|c|c|}
\hline Studi & Lokasi Penelitian & $\mathbf{N}_{i}$ & $\mathbf{r X Y}$ & N x rXY \\
\hline 1 & Italia & 188 & 0,299 & 56,212 \\
\hline 2 & Australia & 180 & 0,19 & 34,200 \\
\hline 3 & Zimbabwe & 30 & 0,483 & 14,490 \\
\hline 4 & Australia & 194 & 0,547 & 106,118 \\
\hline 5 & Portugal & 100 & 0,251 & 25,100 \\
\hline 6 & Malaysia & 61 & 0,614 & 37,454 \\
\hline 7 & Malaysia & 102 & 0,7 & 71,400 \\
\hline 8 & Spanyol & 203 & 0,867 & 176,001 \\
\hline 9 & Pakistan & 257 & 0,46 & 118,220 \\
\hline 10 & Jawa Barat, Indonesia & 167 & 0,391 & 65,297 \\
\hline 11 & Banyumas, Indonesia & 150 & 0,387 & 58,050 \\
\hline 12 & Pakistan & 124 & 0,508 & 62,992 \\
\hline 13 & Meksiko & 125 & 0,687 & 85,887 \\
\hline 14 & Portugal \& Spanyol & 61 & 0,339 & 20,679 \\
\hline 15 & Bosnia \& Herzegovina & 151 & 0,45 & 67,950 \\
\hline 16 & Belanda & 164 & 0,23 & 37,720 \\
\hline 17 & Swedia & 252 & 0,51 & 128,520 \\
\hline 18 & Spanyol & 247 & 0,37 & 91,390 \\
\hline 19 & Spanyol & 354 & 0,361 & 127,637 \\
\hline 20 & Belanda & 152 & 0,32 & 48,640 \\
\hline 21 & Taiwan & 700 & 0,237 & 166,052 \\
\hline 22 & Italia & 250 & 0,265 & 66,250 \\
\hline 23 & United Kingdom & 108 & 0,345 & 37,227 \\
\hline 24 & Malaysia & 284 & 0,448 & 127,232 \\
\hline 25 & Malaysia & 92 & 0,527 & 48,505 \\
\hline \multicolumn{2}{|r|}{ Total } & 4696 & 10,786 & $1.879,222$ \\
\hline \multicolumn{2}{|r|}{ Mean } & 187,84 & 0,431 & 0,400 \\
\hline
\end{tabular}

sampel (N) yang cukup untuk penelitian meta-analisis adalah 3.000 sampel.

b. Menghitung varians $r_{i}$

$$
\sigma_{r}^{2}=\frac{\sum N_{i}\left(r_{i}-r\right)^{2}}{\sum N_{i}}
$$

Tabel 4 berikut menjelaskan lebih lanjut mengenai proses perhitungan untuk varians.

Berdasarkan Tabel 4, diketahui bahwa varians $r_{x y}$ sebesar 0,026 . c. Menghitung varians kesalahan pengambilan sampel

Selanjutnya varians kesalahan pengambilan sampel dihitung dengan lebih dahulu menghitung rata-rata ukuran sampel sesuai persamaan $(4 a)$ berikut:

$\widetilde{N}=\frac{\sum N_{i}}{R}$

Sehingga diperoleh varians kesalahan pengambilan sampel melalui persamaan $(4 b)$ berikut: 


$$
\sigma_{2}^{2}=\frac{\left(1-r^{2}\right)^{2}}{(h-1)}
$$

Varians kesalahan pengambilan sampel pada persamaan (4b) diatas memerlukan nilai rerata korelasi populasi (̌r) dan juga jumlah rerata sampel dari keseluruhan studi. Di bawah ini proses perhitungannya:

$$
\tilde{N}=\frac{2 N_{i}}{K}=\frac{4696}{25}=187,84
$$

$\sigma_{\varepsilon}^{2}=\frac{\left(1-r^{2}\right)^{2}}{(\tilde{N}-1)}=\frac{\left(1-0,4^{2}\right)^{2}}{(187,84-1)}=0,0038$

Varians kesalahan pengambilan sampel $\sigma^{2} e$ sebesar 0,0038 .

Selanjutnya menghitung estimasi varians korelasi setelah dikoreksi dengan kesalahan pengambilan sampel, seperti ditunjukkan pada persamaan (5a).

d. Estimasi varians korelasi terkoreksi kesalahan pengambilan sampel

$\sigma_{\rho o}^{2}=\sigma_{r}^{2}-\sigma_{e}^{2}$

Tabel 4

\begin{tabular}{|c|c|c|c|c|c|c|c|}
\hline Studi & Lokasi Penelitian & $\mathbf{N i}_{\mathrm{i}}$ & $\mathrm{rxy}$ & $\mathbf{N} \times \mathbf{r x y}$ & $r X Y-r$ & $(r X Y-r)^{2}$ & $\mathrm{Nx}(\mathrm{r} X \mathrm{x}-\mathrm{r})^{2}$ \\
\hline 1 & Italia & 188 & 0,299 & 56,212 & $-0,101$ & 0,010 & 1,924 \\
\hline 2 & Australia & 180 & 0,19 & 34,200 & $-0,210$ & 0,044 & 7,951 \\
\hline 3 & Zimbabwe & 30 & 0,483 & 14,490 & 0,083 & 0,007 & 0,206 \\
\hline 4 & Australia & 194 & 0,547 & 106,118 & 0,147 & 0,022 & 4,182 \\
\hline 5 & Portugal & 100 & 0,251 & 25,100 & $-0,149$ & 0,022 & 2,225 \\
\hline 6 & Malaysia & 61 & 0,614 & 37,454 & 0,214 & 0,046 & 2,789 \\
\hline 7 & Malaysia & 102 & 0,7 & 71,400 & 0,300 & 0,090 & 9,169 \\
\hline 8 & Spanyol & 203 & 0,867 & 176,001 & 0,467 & 0,218 & 44,239 \\
\hline 9 & Pakistan & 257 & 0,46 & 118,220 & 0,060 & 0,004 & 0,920 \\
\hline 10 & Jawa Barat, Indonesia & 167 & 0,391 & 65,297 & $-0,009$ & 0,000 & 0,014 \\
\hline 11 & Banyumas, Indonesia & 150 & 0,387 & 58,050 & $-0,013$ & 0,000 & 0,026 \\
\hline 12 & Pakistan & 124 & 0,508 & 62,992 & 0,108 & 0,012 & 1,442 \\
\hline 13 & Meksiko & 125 & 0,687 & 85,887 & 0,287 & 0,082 & 10,291 \\
\hline 14 & Portugal \& Spanyol & 61 & 0,339 & 20,679 & $-0,061$ & 0,004 & 0,228 \\
\hline 15 & Bosnia \& Herzegovina & 151 & 0,45 & 67,950 & 0,050 & 0,002 & 0,375 \\
\hline 16 & Belanda & 164 & 0,23 & 37,720 & $-0,170$ & 0,029 & 4,749 \\
\hline 17 & Swedia & 252 & 0,51 & 128,520 & 0,110 & 0,012 & 3,040 \\
\hline 18 & Spanyol & 247 & 0,37 & 91,390 & $-0,030$ & 0,001 & 0,225 \\
\hline 19 & Spanyol & 354 & 0,361 & 127,637 & $-0,040$ & 0,002 & 0,556 \\
\hline 20 & Belanda & 152 & 0,32 & 48,640 & $-0,080$ & 0,006 & 0,977 \\
\hline 21 & Taiwan & 700 & 0,237 & 166,052 & $-0,163$ & 0,027 & 18,589 \\
\hline 22 & Italia & 250 & 0,265 & 66,250 & $-0,135$ & 0,018 & 4,568 \\
\hline 23 & United Kingdom & 108 & 0,345 & 37,227 & $-0,055$ & 0,003 & 0,332 \\
\hline 24 & Malaysia & 284 & 0,448 & 127,232 & 0,048 & 0,002 & 0,650 \\
\hline 25 & Malaysia & 92 & 0,527 & 48,505 & 0,127 & 0,016 & 1,485 \\
\hline \multicolumn{2}{|r|}{ Total } & 4696 & 10,786 & $1.879,222$ & 0,781 & 0,679 & 121,152 \\
\hline \multicolumn{2}{|r|}{ Mean } & 187,84 & 0,431 & 0,400 & 0,0002 & 0,0001 & 0,026 \\
\hline
\end{tabular}

Perhitungan Varians 


$$
\begin{aligned}
\sigma_{\rho o}^{2} & =\sigma_{r}^{2}-\sigma_{\varepsilon}^{2}=0,026-0,0038 \\
& =0,022
\end{aligned}
$$

Dengan standar deviasi-nya adalah $\sigma_{p o}=\sqrt{0,022}=0,148$

Berdasarkan interval kepercayaan $95 \%$, rasio $\tilde{r}$ terhadap $\sigma_{\rho o}$ sebagai kriteria kelayakan haruslah bernilai lebih besar atau sama dengan 2, seperti ditunjukkan persamaan (5b).

e. Menghitung rasio $r$ terhadap $\sigma_{\rho o}$ sebagai kriteria kelayakan berdasarkan interval kepercayaan 95\%

$$
\begin{aligned}
& \frac{\vec{r}}{\sigma_{\rho \theta}} \geq 2 \\
& \frac{\vec{r}}{\sigma_{\rho}}=\frac{0,4}{0.148}=2,697 \geq 2
\end{aligned}
$$

Berdasarkan hasil diatas, maka nilai dapat diterima, dan analisis dapat dilanjutkan ke koreksi kesalahan pengukuran. Dampak kesalahan pengambilan sampel dihitung menurut persamaan $(5 \mathrm{c})$.

f. Menghitung dampak kesalahan pengambilan sampel

$R_{1}=\frac{\sigma_{p o}^{2}}{\sigma_{T}^{2}}$

dengan

$\check{\mathrm{r}}=$ mean $r_{i}$

$\sigma_{v}^{2}=$ varians $r_{i}$

$\vec{N}$ = rata-rata ukuran sampel

$K=$ jumlah studi

$\sigma_{e}^{2}=$ varians kesalahan pengambilan sampel

$\sigma_{p o}^{2}=$ varians korelasi terkoreksi kesalahan pengambilan sampel

$\sigma_{\rho o}=$ standar deviasi korelasi terkoreksi

$R_{1}=$ dampak kesalahan pengambilan sampel

Proses perhitungannya sebagai berikut:

$$
R_{1}=\frac{\sigma_{\rho o}^{2}}{\sigma_{r}^{2}}=\frac{0,022}{0,026}=0,8537
$$

Dari perhitungan ini diperoleh kesimpulan bahwa reliabilitas (keandalan) nilai korelasi adalah sebesar $85,37 \%$, atau varians kesalahan pengambilan sampel sebesar $14,633 \%$. Nilai ini menunjukkan bahwa hasil pengukuran dengan pendekatan meta-analisis ini memiliki tingkat keandalan yang cukup besar.

3. Melakukan koreksi kesalahan pengukuran. Langkah-langkah dalam menghitung koreksi kesalahan pengukuran adalah sebagai berikut:

a. Menghitung rata-rata gabungan dari reliabilitas pengukuran $x$ dan $y$

$$
\begin{aligned}
& a=\sqrt{r_{x x}} \\
& b=\sqrt{r_{y y}} \\
& \ddot{a}=\frac{\Sigma a}{\Sigma N_{x}} \\
& \check{b}=\frac{\Sigma b}{\Sigma N_{b}} \\
& \tilde{A}=\ddot{a} \bar{b}
\end{aligned}
$$

Proses perhitungannya ditampilkan pada Tabel 5.

Tabel 5

Perhitungan Rata-rata Gabungan dari Reliabilitas Pengukuran

\begin{tabular}{ccccc}
\hline Studi & $r x x$ & $($ a $)$ & $r y y$ & $($ b $)$ \\
\hline 1 & & & & \\
2 & 0,88 & 0,938 & 0,82 & 0,906 \\
3 & & & & \\
4 & 0,87 & 0,933 & 0,9 & 0,949 \\
5 & & & & \\
6 & & & & \\
7 & 0,96 & 0,980 & 0,9 & 0,949 \\
8 & 0,89 & 0,943 & 0,9 & 0,949 \\
9 & 0,79 & 0,889 & 0,83 & 0,911 \\
\hline
\end{tabular}




\begin{tabular}{rrrrr}
\hline 10 & & & & \\
11 & 0,994 & 0,997 & 0,987 & 0,993 \\
12 & 0,91 & 0,954 & 0,93 & 0,964 \\
13 & & & & \\
14 & & & & \\
15 & 0,9 & 0,949 & 0,9 & 0,949 \\
16 & 0,69 & 0,831 & 0,75 & 0,866 \\
17 & 0,83 & 0,911 & 0,93 & 0,964 \\
18 & & & & \\
19 & 0,9 & 0,949 & 0,9 & 0,949 \\
20 & & & & \\
21 & & & & \\
22 & & & & \\
23 & 0,83 & 0,911 & 0,85 & 0,922 \\
24 & & & & \\
25 & 0,841 & 0,917 & 0,841 & 0,917 \\
\hline Total & 11,285 & 12,101 & 11,438 & 12,187 \\
\hline Mean & 0,868 & 0,931 & 0,880 & 0,937 \\
\hline SD & 0,076 & 0,042 & 0,060 & 0,033 \\
\hline
\end{tabular}

Rata-rata gabungan dari reliabilitas pengukuran $x$ dan $y$ dihitung dengan terlebih dahulu menghitung nilai $\mathrm{a}, \mathrm{b}, \breve{a}$, dan $\breve{\mathrm{b}}$ menurut persamaan (6a), (6b), (6c), dan (6d). Berikut proses perhitungannya:

$$
\ddot{a}=\frac{\sum a}{\sum N_{a}}=\frac{12,101}{13}=0,931
$$

dan

$$
\breve{b}=\frac{\sum^{2} b}{\sum N_{b}}=\frac{12,187}{13}=0.937
$$

Sehingga rerata gabungan dapat dihitung melalui persamaan (6e) dengan hasil berikut:

$$
A=\check{a} \breve{b}=(0.931)(0.937)=0.873
$$

b. Menghitung korelasi terkoreksi kesalahan pengukuran

$$
\begin{aligned}
& \rho=\frac{\vec{r}}{A} \\
& \rho=\frac{\check{r}}{\mathscr{A}}=\frac{0,4}{0,673}=0,459
\end{aligned}
$$

Setelah dilakukan koreksi terhadap artefak pengukuran, diperoleh estimasi korelasi ( $\rho$ ) sebesar 0,459. Dari analisis tersebut, dapat disimpulkan bahwa secara keseluruhan pada data sampel yang dijadikan unit analisis, terdapat hubungan yang kuat antara inovasi dengan kinerja Industri Kecil dan Menengah.

c. Menghitung varians kesalahan pengukuran

Penghitungan koefisien ini dengan menjumlahkan koefisien kuadrat varians baik yang terdapat pada variabel independen (a) dan dependen (b), seperti yang ditunjukkan pada persamaan (8) berikut:

$$
\begin{aligned}
& V=\frac{a_{a}^{2}}{a^{2}}+\frac{\sigma_{b}^{2}}{b^{2}} \\
& V=\frac{\sigma_{a}^{2}}{a^{2}}+\frac{\sigma_{b}^{2}}{b^{2}}=\frac{0,042^{2}}{0,931^{2}}+\frac{0,033^{2}}{0,937^{2}}=0,0032
\end{aligned}
$$

d. Varians yang mengacu variasi artefak

$$
\begin{aligned}
a_{2}^{2} & =\rho^{2} A^{2} V \\
a_{2}^{2} & =p^{2} A^{2} V \\
& =\left(0,459^{2}\right)\left(0,873^{2}\right)(0,0032) \\
& =0,00051
\end{aligned}
$$

e. Estimasi varians sesungguhnya

$$
\begin{gathered}
\sigma_{\rho}^{2}=\frac{\sigma_{\rho Q}^{2}-\sigma_{2}^{2}}{A^{2}} \\
\sigma_{\rho}^{2}=\frac{\sigma_{\rho o}^{2}-\sigma_{2}^{2}}{A^{2}}=\frac{0,022-0,00051}{0,873^{2}}=0,028
\end{gathered}
$$

Standar deviasinya $=\sqrt{0,028}=0,168$

f. Menghitung rasio $\rho$ terhadap $\sigma_{\rho}$ sebagai kriteria kelayakan berdasarkan interval kepercayaan 95\%

$$
\begin{aligned}
& \frac{p}{\sigma_{p}} \geq 2 \\
& \frac{\rho}{\sigma_{p}}=\frac{0,459}{0,168}=2,73 \geq 2
\end{aligned}
$$


Karena nilai $\frac{p}{\sigma_{s}} \geq 2$, maka berarti terdapat korelasi + (positif) antara inovasi dengan kinerja IKM. Artinya semakin baik inovasi yang dilakukan didalam internal perusahaan IKM, maka akan semakin meningkat kinerja perusahaan tersebut.

g. Menghitung dampak kesalahan pengukuran

$1-R_{2}=\frac{\sigma_{2}^{2}}{\sigma_{0}^{2} a}$

$1-R_{2}=\frac{\sigma_{2}^{2}}{\sigma_{p o}^{2}}=\frac{0,00051}{0,022}=0,0233$

Varians kesalahan pengukuran sebesar 2,33\% (cukup kecil).

dengan

$r_{x x}=$ reliabilitas pengukuran $x$

$r_{y y}=$ reliabilitas pengukuran $y$

$a=$ akar reliabilitas pengukuran $x$

$b=$ akar reliabilitas pengukuran $y$

$\check{a}=$ rata-rata $a$

$\check{b}=$ rata-rata $b$

$N_{a}=$ jumlah data $a$

$N_{b}=$ jumlah data $b$

$\hat{A}=$ rata-rata gabungan $a$ data $b$

$\rho=$ korelasi sesungguhnya

$V=$ jumlah kuadrat varians

$\sigma_{2}^{2}=$ varians kesalahan pengukuran

$\sigma_{\rho}^{2}=$ varians korelasi sesungguhnya

$\sigma_{\rho}=$ standar deviasi korelasi sesungguhnya

$R_{2}=$ dampak kesalahan pengukuran

Tahun Penelitian Sebagai Variabel Moderator

Jika

dilakukan

Tabel 7

Korelasi Berdasarkan Lokasi Penelitian

Tabel 6

Benua

$\mathrm{Ni} \quad \rho-1,96 \sigma_{\rho}$

$\rho$

$\rho+1,96 \sigma_{\rho}$

$1,96 \sigma_{\rho}$

Korelasi Berdasarkarerfikhun Penelitiar25

\begin{tabular}{|c|c|c|c|c|c|c|c|}
\hline Tahun & $\mathrm{A}_{i}$ frika & $\rho-1,96 \sigma_{\rho}$ & $30 \rho$ & $\rho+1,96 \sigma_{\rho}$ & $1,96 \sigma_{\rho}$ & & \\
\hline 2004-2007 & 1154pa & 0,134 & 2230,360 & $0,108,586$ & $0,464,226$ & 0,819 & 0,355 \\
\hline 2008-2010 & $1039^{1}$ & & 1937,365 & 0,175 & 0,435 & 0,694 & 0,260 \\
\hline 2011-2013 & 2503 stra & & 374,540 & 0,057 901 & 0,433 & 0,809 & 0,376 \\
\hline
\end{tabular}


inovasi dengan kinerja perusahaan, pada benua Amerika dan Afrika tidak dapat disimpulkan apakah positif atau negatif. Hal ini juga disebabkan keterbatasan data sampel penelitian mengenai kedua benua tersebut. Jika dilihat pada benua Eropa, Asia dan Australia, terdapat korelasi positif antara inovasi dengan kinerja perusahaan, dengan mean masing-masing 0,464, 0,435 dan 0,433.

Pada penelitian di beberapa negara Asia, proses interaksi (pola komunikasi) yang dibangun dalam perusahaan dan hubungan kekerabatan dalam pengelolaan IKM dapat mempengaruhi kemampuan inovasi yang dapat meningkatkan kinerja perusahaan secara keseluruhan.

\section{Pembahasan}

Pada kajian meta-analisis ini, unit kajian didominasi oleh penelitian yang dipublikasikan pada rentang tahun 2011 hingga 2013, sedangkan lokasi penelitian lebih didominasi pada penelitian yang dilakukan di Eropa dan Asia. Kondisi ini ditunjukkan pada Gambar 3 dan 4.

Hasil kajian meta-analisis atas korelasi antara inovasi dengan kinerja perusahaan ini, memberikan nilai korelasi positif dengan mean sebesar 0,459 (korelasi terkoreksi kesalahan pengukuran) dan standar deviasi sebesar 0,168, pada rentang inter- val kepercayaan 95\%. Rasio antara mean dan standar deviasi korelasi memberikan nilai lebih besar dari 2 (dua), sehingga dapat disimpulkan bahwa hasil metaanalisis ini dapat diterima. Dengan demikian dapat disimpulkan bahwa $\mathrm{H}_{1}$ dapat diterima atau dapat dikatakan bahwa inovasi berkorelasi positif dengan kinerja perusahaan. Artinya semakin baik inovasi yang dilakukan didalam internal perusahaan (baik product, process, atau service), akan memberikan pengaruh positif terhadap kinerja (performansi) perusahaan.

Untuk variabel moderator "tahun penelitian", diketahui bahwa pada tahun 2011-2013 dan tahun 2004-2002 terdapat korelasi positif antara inovasi dengan kinerja perusahaan, namun tahun 20082010 tidak dapat disimpulkan apakah berkorelasi positif atau negatif, sehingga dapat dikatakan bahwa $\mathrm{H}_{2}$ berkorelasi untuk beberapa kondisi $\left(\mathrm{H}_{2}\right.$ : tahun penelitian berkorelasi positif dengan kinerja perusahaan). Untuk variabel moderator "lokasi penelitian" diketahui bahwa pada benua Eropa, Asia dan Australia, terdapat korelasi positif antara inovasi dengan kinerja perusahaan, akan tetapi pada benua Amerika dan Afrika tidak dapat disimpulkan apakah berkorelasi positif atau negatif, sehingga $\mathrm{H}_{3}$ juga berkorelasi pada beberapa kondisi $\left(\mathrm{H}_{3}\right.$ : lokasi penelitian berkorelasi positif dengan kinerja perusahaan). 


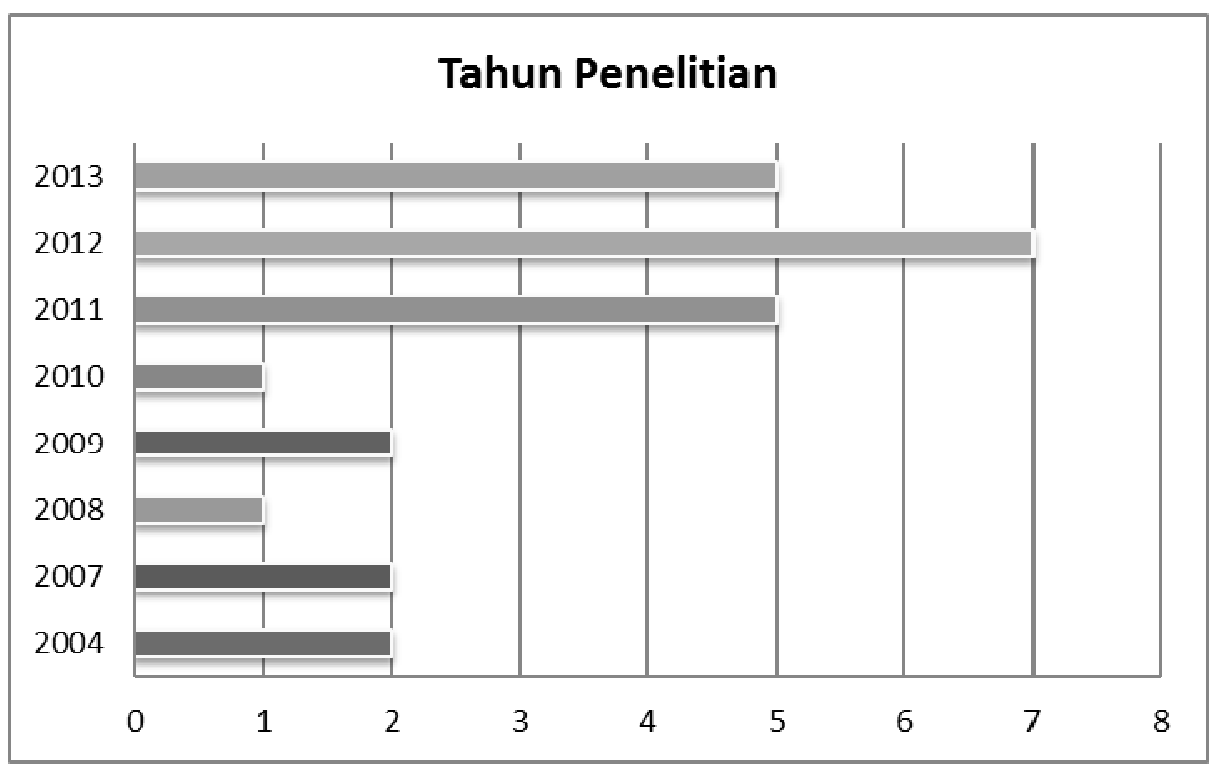

Gambar 3. Studi Kajian Berdasarkan Tahun Penelitian

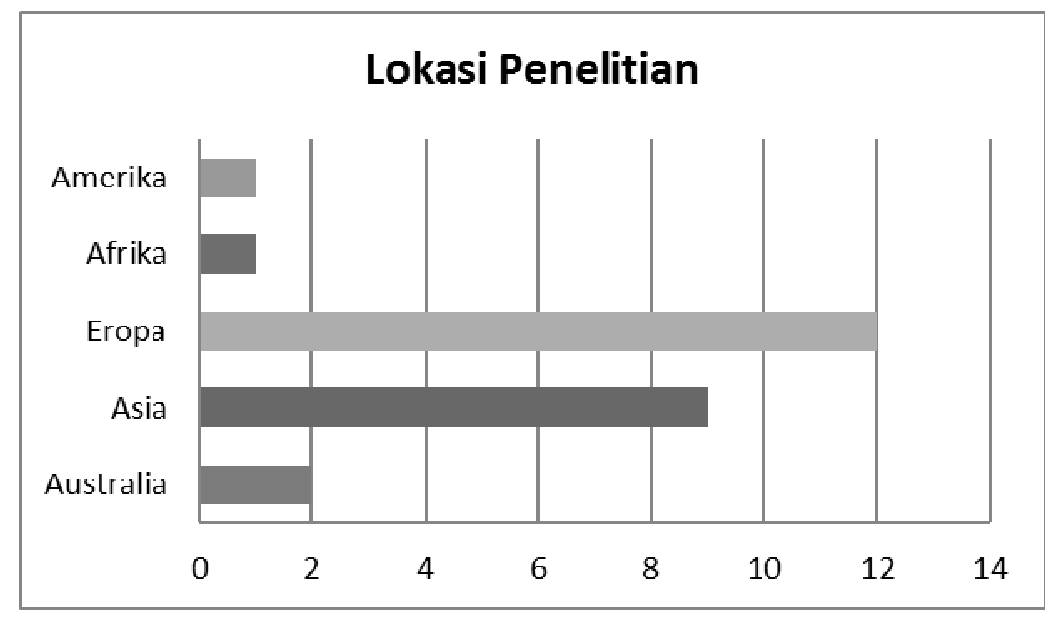

Gambar 4. Studi Kajian Berdasarkan Lokasi Penelitian

Pengaruh kultur budaya dimana perusahaan beroperasi, juga dapat mempengaruhi hubungan antara inovasi dan kinerja, walaupun dalam kajian ini tidak dapat dibuktikan secara nyata (disebabkan keterbatasan data). Namun berdasarkan review beberapa sampel studi, ditemukan bahwa inovasi memiliki dampak positif terkuat di lingkungan budaya yang ditandai dengan kolektivisme seperti yang ditemukan di banyak negara Asia. Sebaliknya, dalam budaya yang lebih individualistis seperti di Eropa dan Amerika, hubungan antara inovasi dan kinerja sangat lemah.

\section{Penutup}

Berdasarkan hasil literatur review (studi empiris), ditemukan bahwa hubungan antara innovation (inovasi) dan performance (kinerja) tergantung konteks. Dalam konteks pertama bahwa inovasi tidak mempengaruhi kinerja perusahaan atau menemukan implikasi negatif antara inovasikinerja, sementara itu pada kontes kedua 
terdapat efek positif (hubungan positif) antara inovasi dengan kinerja. Hasil reviu tentang penelitian hubungan inovasi terhadap kinerja perusahaan/IKM menggambarkan hal yang saling bertentangan.

Studi meta-analisis yang dilakukan ini memperkuat hipotesis umum bahwa inovasi berpengaruh secara nyata terhadap kinerja perusahaan, khususnya pada IKM (variabel independen adalah inovasi, sedangkan variabel dependen adalah kinerja). Review dilakukan pada penelitian yang dipublikasikan antara Tahun 2004 sampai 2013, dengan lokasi survei pada lima benua (Australia, Asia, Eropa, Afrika dan Amerika). Hasil studi meta-analisis ini secara umum memberikan hasil nilai korelasi positif, dengan mean 0,459 dan standar deviasi 0,168 pada interval kepercayaan $95 \%$.

Variabel moderator "tahun penelitian" menunjukkan korelasi positif untuk beberapa kondisi, sedangkan variabel moderator "lokasi penelitian" juga menunjukkan korelasi pada lokasi penelitian tertentu, sehingga dapat disimpulkan bahwa korelasi inovasi dan kinerja sangat tergantung konteks.

Berdasarkan kajian meta-analisis ini, menunjukkan kenyataan bahwa banyaknya sampel penelitian (jumlah literatur yang dikaji) sangat memengaruhi analisis sensivitas data dan power dari penelitian, karena memberikan efek yang cukup signifikan. Hasil kajian meta-analisis ini juga membuka peluang bagi studi metaanalisis selanjutnya, misalnya pengaruh inovasi terhadap kinerja pada perusahaan besar atau pengaruh inovasi terhadap peningkatan daya saing (competitiveness) pada industri kreatif.

\section{Daftar Pustaka}

Carbonell, P., \& Escudero, A. I. R. (2010). The Effect of Market Orientation On Innovation Speed and New Product Performance. The Journal of Business $\mathcal{E}$ Industrial Marketing, 25(7), 501-513.

Cruz, N. M., Escudero, A. I. R., Barahona, J. H., \& Leitao, F. S. (2009). The Effect of Entrepreneurship Education Programmes on Satisfaction with Innovation Behaviour and Performance. Journal of European Industrial Training, 33(3), 198-214.

Dorrego, P. F., Costa, R., \& Fernández, C. F. (2013). The Influence of Relational Capital on Product Innovation Performance at Innovative SMEs. Paper presented at the 91-X. Diunduh dari: http://search.proquest.com/docview/1 368589675? accountid $=13771$

Eisenhardt, K. M., \& Martin, J. A. (2000). Dynamic capabilities: what are they?. Strategic Management Journal, 21(11), 1105-1121.

Ferreira, J., Raposo, M., \& Fernandes, C. (2012). The Influence of Innovative Capacity on Firms Performance: Portuguese and Spanish Evidences. Paper presented at the 226-XIV. Diunduh dari: http:// search.proquest.com/docview/1325747 012 ? accountid $=13771$

Gaynor, G. H. (2002), Innovation by Design: What it Takes to Keep Your Company on The Cutting Edge, AMACOM American Management Association, New York.

Gomez, J., Llonch, J., \& Rialp, J. (2011). Strategic Orientation, Innovation and Performance of New SMEs. GSTF Business Review (GBR), 1(2), 76-79.

Guzmán, G. M., Serna, M. D. C. M., \& Lema, D. G. P. (2012). The Relationship Between Knowledge Management and Innovation Level in Mexican SMEs: Empirical Evidence. Paper presented at the 
659-XX. Diunduh dari: http://search. proquest.com/docview/1326757177 accountid $=13771$

Hunter, J.E., \& Schmidt, F. L. (2004). Methods of Meta-Analysis: Correcting Error and Bias in Research Findings. 2nd edition. Sage Publications, Inc., California.

Kraus, S., Rigtering, J. P., C., Hughes, M., \& Hosman, V. (2012). Entrepreneurial Orientation and The Business Performance of SMEs: A Quantitative Study from The Netherlands. Review of Managerial Science, 6(2), 161-182.

Lin, C. Y., \& Chen, M. Y. (2007). Does Innovation Lead to Performance? An Empirical Study of SMEs in Taiwan. Management Research News, 30(2), 115132.

Mancinelli, S., \& Mazzanti, M. (2009). Innovation, Networking and Complementarity: Evidence on SME Performances for a Local Economic System in North-Eastern Italy. The Annals of Regional Science, 43(3), 567-597.

Marcati, A., Guidoa, G., \& Peluso, A. M. (2008). The role of SME entrepreneurs' innovativeness and personality in the adoption of innovations. Research Policy, 37, 1579-1590.

Massa, S., \& Testa, S. (2008), Innovation and SMEs: Misaligned Perspective and Goals Among Entrepreneurs, Academic, and Policy Makers. Journal of Technovation, 28, 393-407.

Matic, I., \& Jukic, V. (2012). Innovativeness and Business Performances: Empirical Evidence from Bosnia and Herzegovina's Small-Sized Firms. Journal of American Academy of Business, Cambridge, 18(1), 198-205.

Mbizi, R., Hove, L., Thondhlana, A., \& Kakava, N. (2013). Innovation in SMEs: A review of Its Role to Organ- isational Performance and SMEs Operations Sustainability. Interdisciplinary Journal of Contemporary Research in Business, 4(11), 370-389.

McDermott, C. M., \& Prajogo, D. I. (2012). Service Innovation and Performance in SMEs. International Journal of Operations \& Production Management, 32(2), 216-237.

Moghimi, S., \& Subramaniam, I. D. (2013). Employees Creative Behavior: The Role of Organizational Climate in Malaysian SMEs. International Journal of Business and Management, 8(5), 1-12.

Muscio, A. (2006). Patterns of Innovation in Industrial Districts: An Empirical Analysis. Industry and Innovation, 13(3), 291-312.

Najib, M., \& Kiminami, A. (2011). Innovation, Cooperation and Business Performance. Journal of Agribusiness in Developing and Emerging Economies, 1(1), 75-96.

Ndubisi, N. O., \& Iftikhar, K. (2012). Relationship Between Entrepreneurship, Innovation and Performance. Journal of Research in Marketing and Entrepreneurship, 14(2), 214-236.

Oke, A., Burke, G., \& Myers, A. (2007). Innovation Types and Performance in Growing UK SMEs. International Journal of Operations \& Production Management, Vol. 27, No. 7, pp. 735-753.

Okwiet, B., \& Grabara, J. K. (2013), Innovations Influence on SME Enterprises Activities. Procedia Economics and Finance, 6, 194-204.

Parida, V., Westerberg, M., \& Frishammar, J. (2011). Effect of Open Innovation Practices on SMEs Innovative Performance: An Empirical Study. Paper presented at the 1-20. Diunduh dari: http://search. proquest.com/docview/922574831?acc ountid=13771 
Porter, M. E., \& Stern, S. (2001). Innovation: location matters. Review MIT Sloan Management, 42(4), 28-36.

Prajogo, D. I., Power, D. J., \& Sohal, A. S. (2004). The Role of Trading Partner Relationships in Determining Innovation Performance: An Empirical Examination. European Journal of Innovation Management, 7(3), 178-186.

Rajput, A. A. (2011). Impact of Innovation and Resources in Entrepreneurial Success: A Case Study of Pakistani SMEs. Interdisciplinary Journal of Contemporary Research in Business, 2(11), 606-636.

Rosenbusch, N., Brinckmann, J., \& Bausch, A. (2011). Is Innovation Always Beneficial? A Meta-Analysis of the Relationship Between Innovation and Performance in SMEs. Journal of Business Venturing, 26, 441-457.

Rosli, M. M., \& Mahmood, R. (2013). Moderating Effects of Human Resource Management Practices and Entrepreneur Training on Innovation and Small-Medium Firm Performance. Journal of Management and Strategy, 4(2), 60-69. DOI: 10.5430/jms.v4n2p60

Salim, I. M., \& Sulaiman, M. (2011). Organizational Learning, Innovation and
Performance: A Study of Malaysian Small and Medium Sized Enterprises. International Journal of Business and Management, 6(12), 118-125.

Subramaniam, I. D., \& Moslehi, M. M. (2013). Does Workforce Innovation Mediate the Relationship Between Internal Factors and Performance in Malaysian Entrepreneurial SMEs? Asian Social Science, 9(9), 45-63.

Suliyanto, S., \& Rahab, R. (2012). The Role of Market Orientation and Learning Orientation in Improving Innovativeness and Performance of Small and Medium Enterprises. Asian Social Science, 8(1), 134-145.

Tomlinson, P. R., \& Fai, F. M. (2013). The Nature Of SME Co-Operation And Innovation: Amulti-Scalar And MultiDimensional Analysis. International Journal of Production Economics, 141, 316-326.

Verhees, F. J. H. M., \& Meulenberg, M. T. G. (2004). Market Orientation, Innovativeness, Product Innovation, and Performance in Small Firms. Journal of Small Business Management, 42(2), 134154. 